\title{
Detecting Wheat Powdery Mildew and Predicting Grain Yield Using Unmanned Aerial Photography
}

Wei Liu, State Key Laboratory for Biology of Plant Diseases and Insect Pests, Institute of Plant Protection, Chinese Academy of Agricultural Sciences, Beijing 100193, China; Xueren Cao, Key Laboratory of Integrated Pest Management on Tropical Crops, Ministry of Agriculture, Environment and Plant Protection Institute, Chinese Academy of Tropical Agricultural Sciences, Haikou 571101, China; Jieru Fan, Zhenhua Wang, and Zhengyuan Yan, State Key Laboratory for Biology of Plant Diseases and Insect Pests, Institute of Plant Protection, Chinese Academy of Agricultural Sciences, Beijing 100193, China; Yong Luo, Department of Plant Pathology, China Agricultural University, Beijing 100193, China; Jonathan S. West, Rothamsted Research, Harpenden, AL5 2JQ, UK; Xiangming Xu, ${ }^{\dagger}$ NIAB EMR, New Road, East Malling, Kent ME19 6BJ, UK; and Yilin Zhou, ${ }^{\dagger}$ State Key Laboratory for Biology of Plant Diseases and Insect Pests, Institute of Plant Protection, Chinese Academy of Agricultural Sciences, Beijing 100193, China

\begin{abstract}
High-resolution aerial imaging with an unmanned aerial vehicle (UAV) was used to quantify wheat powdery mildew and estimate grain yield. Aerial digital images were acquired at Feekes growth stage (GS) 10.5.4 from flight altitudes of 200,300, and $400 \mathrm{~m}$ during the 2009-10 and 2010-11 seasons; and 50,100, 200, and $300 \mathrm{~m}$ during the 2011-12, 2012-13, and 2013-14 seasons. The image parameter lgR was consistently correlated positively with wheat powdery mildew severity and negatively with wheat grain yield for all combinations of flight altitude and year. Fitting the data with random coefficient regression models

showed that the exact relationship of $\lg \mathrm{R}$ with disease severity and grain yield varied considerably from year to year and to a lesser extent with flight altitude within the same year. The present results raise an important question about the consistency of using remote imaging information to estimate disease severity and grain yield. Further research is needed to understand the nature of interyear variability in the relationship of remote imaging data with disease or grain yield. Only then can we determine how the remote imaging tool can be used in commercial agriculture.
\end{abstract}

Wheat powdery mildew, caused by the obligate fungi Blumeria graminis f. sp. tritici $(B g t)$, is one of the most important wheat diseases in the world. Host resistance and fungicides have been the main management strategies for wheat powdery mildew (Opalski et al. 2006; Petersen 2015; Wolfe 1984). Fungicide application is still essential for disease management because varieties often lose their resistance in a relatively short period of time due to the rapid emergence of new virulent pathogen races (Schepers et al. 1996). Rapid and accurate monitoring the severity of wheat powdery mildew is of great importance for disease management.

There has been increasing interest in using ground-based prototypes of hyperspectral (Cao et al. 2013, 2015; Franke and Menz 2007; Zhang et al. 2012) and satellite remote sensing technologies (Mirik et al. 2011; Nagarajan et al. 1984; Nilsson 1995; Zhang et al. 2014) to monitor plant diseases. Compared with the groundbased prototype of hyperspectral and satellite remote sensing technologies, unmanned aerial imaging achieves a good balance between area coverage and image resolution (Li et al. 2012). Airborne sensor data have been widely used to survey disease development, such as cereal rust (Colwell 1956), bacterial blight of field beans (Wallen and Jackson 1971), cotton root rot (Toler et al. 1981), and spot blotch of barley (Clark et al. 1981). These studies depended mainly on photographic film due to the limitation of technology at the time, which

${ }^{\dagger}$ Corresponding authors: Y. L. Zhou, E-mail: ylzhou@ippcaas.cn; and X. M. Xu, E-mail: Xiangming.Xu@emr.ac.uk

Funding: This work was financially supported by the National Key Research and Development Program of China (2018YFD0200500), National Natural Science Foundation of China (31671966), Special Fund for Agro-scientific Research in the Public Interest (20130316). X. M. Xu was supported by Science and Technology Facilities Council (STFC) under Newton Fund with grant number ST/N006852/1. J. S. West works on the Smart Crop Protection strategic programme (BBS/OS/CP/000001) funded by the BBSRC Industrial Strategy Challenge Fund.

Accepted for publication 11 April 2018.

() 2018 The American Phytopathological Society made image processing and information extraction complicated. Recent development of remote sensing technology has opened new avenues for applying the technology in agriculture; one example is the use of smaller, autonomous aerial platforms capable of flying at low altitudes while carrying a diverse set of miniaturized sensors (Berni et al. 2009; Garcia-Ruiz et al. 2013; Zarco-Tejada et al. 2012).

Image analysis of aerial digital photographs has appeared in the agronomic literature in the last 20 years. Everitt et al. (1999) used airborne digital imagery to detect oak wilt disease. Martins et al. (2001) suggested that small-format aerial photography acquired from a $400 \mathrm{~m}$ flight altitude is an effective tool for monitoring chestnut ink disease. Aerial photography coupled with spatial analyses of late blight-infected plants was effective for quantifying disease patterns between different years (Johnson et al. 2003). Low altitude aerial imagery can detect laurel wilt disease in avocado at an average flight altitude of $60 \mathrm{~m}$ above the ground (de Castro et al. 2015). Readily available and inexpensive computers, digital cameras, and software packages make this method an attractive option (Steddom et al. 2004). Many studies have been carried out to predict wheat grain yield using remote sensing information at different crop growth stages (Aparicio et al. 2000; Babar et al. 2006; Cao et al. 2014), including the use digital images taken with unmanned aerial vehicles (Jannoura et al. 2015; Shanahan et al. 2001; Vega et al. 2015).

Most previous studies focused on the feasibility of using unmanned aerial photography to detect plant diseases and predict crop yield, but have rarely considered the variability (or consistency) of such predictive relationships. Without such knowledge, it would be difficult to assess how widely a given relationship could be used in practice. The purpose of the present study was to determine the extent of variability of using unmanned aerial photography to estimate wheat powdery mildew severity and grain yield between different flight altitudes over multiple years.

\section{Materials and Methods}

Plot design and yield determination. Field experiments were conducted at the Langfang Experimental Station, Institute of Plant Protection, Chinese Academy of Agricultural Sciences $\left(39.5^{\circ} \mathrm{N}\right.$, $116.6^{\circ} \mathrm{E}$ ) in Hebei Province, China, in 2009-10, 2010-11, 2011-12, 2012-13, and 2013-14. Jingshuang 16, a winter wheat cultivar highly 
susceptible to powdery mildew, was sown in rows (interrow distance of $0.25 \mathrm{~m}$ ) with seeding rates of $120 \mathrm{~kg} / \mathrm{ha}$ on 6 October in each year. There were six fungicide treatments (six concentrations of triadimefon $\left[300,240,120,60,30\right.$, and $15 \mathrm{~g}$ active ingredient $\left.\mathrm{ha}^{-1}\right]$ ) and one untreated control. A random block design (with three blocks) was used; in total, there were 21 plots, and each plot was $5 \mathrm{~m}$ long and $4 \mathrm{~m}$ wide. Seedlings (sown in $10-\mathrm{cm}$ pots) with sporulating Bgt lesions were maintained in a greenhouse compartment and transplanted to the center of each plot on 2 April 2010, 25 March 2011, 23 March 2012, 22 March 2013, and 22 March 2014 as spreaders to ensure powdery mildew development. The number of pots with Bgt spreaders corresponded to the concentrations of triadimefon for each plot: $6,5,4,3,2,1$, and 0 pots $\operatorname{plot}^{-1}$ for $0,15,30,60$, 120,240 , and $300 \mathrm{~g}$ active ingredient of triadimefon $\mathrm{ha}^{-1}$, respectively. This combination of triadimefon concentration and inoculum strength was used to create varying severities of powdery mildew. No other diseases and pests occurred in the field plots during the experimental periods.

The fungicide triadimefon was applied at an appropriate concentration on 13 April 2010, 15 April 2011, 12 April 2012, 11 April 2013, and 11 April 2014. Control plots were sprayed with water. Manual weeding was carried out. At the harvest time, a subplot of 10 consecutive rows in each plot was randomly selected for harvesting. Grains were threshed and dried under the sun before weighing.

Disease assessment. Disease severities of powdery mildew were assessed at growth stage (GS) 10.5.4 (Large 1954). Five positions in each plot (four at the corners and one at the center) were chosen for disease assessment; 20 plants at each position were assessed on a 0 to 9 scale (Saari and Prescott 1975; Sheng and Duan 1991). A total of 100 plants were assessed for each plot. Disease index (DI) for a plot was estimated as:

$$
D I=\frac{\sum_{i=0}^{i=9} i * n_{i}}{9 * \sum_{i=0}^{i=9} n_{i}} \times 100
$$

where $\mathrm{n}_{0}, \mathrm{n}_{1} \ldots \mathrm{n}_{9}$ are the number of plants with mildew severity values of $0,1 \ldots 9$, respectively.

Acquisition of unmanned aerial digital image. Table 1 summarizes imagery acquisition in all the years. In 2009-10 and 2010-11, a Canon EOS 500D camera (Canon Inc., Japan) was mounted on a fixed-wing unmanned aerial vehicle (YUYAN-09 UAV, Zero Tech Inc., China). This vehicle was controlled by an autopilot computer and programmed to capture digital images at user-selected viewpoints to ensure complete coverage of the field. The speed of the UAV was nearly $50 \mathrm{~km} / \mathrm{h}$. The location of the aircraft and approximate altitude of the pictures were recorded by a GPS installed on the UAV. In 2011-12, digital images were taken with a Canon EOS 500D camera fitted to an eight-rotor UAV. In 2012-13 and 2013-14, unmanned aerial digital images were taken with Canon EOS 5D Mark II (Canon Inc., Japan) and Panasonic DMC-GH3 (Panasonic Inc., Japan) cameras, respectively. All the cameras were pointed in the vertical viewing. Disease severity was first assessed before aerial imagery which was taken on clear, sunny noon times between 11:00 $\mathrm{h}$ and 13:00 $\mathrm{h}$ (Beijing time, GMT +8:00) from 200, 300 , and $400 \mathrm{~m}$ above the ground level in 2009-10 and 2010-11, and from 50,100, 200, and $300 \mathrm{~m}$ above the ground in 2011-12, 2012-13, and 2013-14 seasons. All images were saved in JPEG format at the highest quality option allowed by their cameras, with image size of $4,272 \times 2,848$ pixels and $35 \mathrm{~mm}$ focal length in 2009-10,
$4,752 \times 3,168$ pixels and $50 \mathrm{~mm}$ focal length in $2010-11,4,752 \times$ 3,168 pixels and $35 \mathrm{~mm}$ focal length in $2011-12,5,616 \times 3,744$ pixels and $24 \mathrm{~mm}$ focal length in $2012-13$, and 4,608 $\times 2,592$ pixels and $15 \mathrm{~mm}$ focal length in 2013-14.

Separating soil background from wheat canopy. We used the maximum likelihood classification, a commonly used method in supervised classification, to reduce the influence of soil background on information extraction from unmanned aerial digital images (ERDAS software, ERDAS, Inc., United States). After supervised classification, data were subjected to the mask processing (ERDAS software, ERDAS, Inc., United States) to extract only the information on the wheat canopy for subsequent statistical analysis.

Extracting information from digital images. Each pixel recorded three primary colors: red $(\mathrm{R})$, green $(\mathrm{G})$, and blue $(\mathrm{B})$, all in the range of 0 to 255 . These three primary colors are usually used in the case of light sources such as color monitors; other secondary colors can be derived by mixing RGB primary colors in different proportions. The observed colors through our human eyes belong to the secondary colors (Gonzalez and Wintz 2001), such as white or gray powdery mildew colonies. ERDAS software was used to extract $\mathrm{R}, \mathrm{G}$, and $\mathrm{B}$ values from each masked digital image.

The HSI (hue-saturation-intensity) system is another commonly used color space in image processing and is directly related to RGB values (Huntsherger et al. 1985; Kim and Park 1996). In the HSI color space, $\mathrm{H}$ (hue) represents the basic colors, with values from $0^{\circ}$ to $360^{\circ} ; \mathrm{S}$ (saturation) is a measure of the purity of the color from $0 \%$ (gray) to $100 \%$ (fully saturated); and I (intensity) describes the brightness of an image and is the sum of the light of all wavelengths within the visible spectrum (Cheng et al. 2001; Kampmann and Hansen 1994; Karcher and Richardson 2003).

RGB values can be transformed to HSI values by the following formulas (Gonzalez and Wintz 2001):

$$
\begin{aligned}
& I=\frac{R+G+B}{3} \\
& \left\{\begin{array}{l}
H=W, \quad B \leq G \\
H=360^{\circ}-W, \quad B>G
\end{array}\right. \\
& S=1-\frac{3 \min (R, G, B)}{R+G+B} \\
& W=\operatorname{COS}^{-1}\left(\frac{2 R-G-B}{2 \sqrt{(R-G)^{2}+(R-B)(G-B)}}\right)
\end{aligned}
$$

RGB values need to be normalized to the range of $[0,1]$ before applying the above formulas; this can be done with the equation

$$
y=\frac{x}{255}
$$

where $x$ and $y$ represent the RGB values before and after normalization, respectively.

The ratio $\mathrm{G} / \mathrm{R}$ was previously proposed as one imaging variable to characterize winter wheat canopy (Adamsen et al. 1999). In addition to this ratio, two other composite variables, $\mathrm{G}-\mathrm{R}$ and $(\mathrm{G}-\mathrm{R}) /(\mathrm{G}+\mathrm{R})$,

\begin{tabular}{|c|c|c|c|c|c|}
\hline Season & Flight altitude & Unmanned aerial vehicle & Camera & Camera resolution & Focal length \\
\hline $2009-10$ & $200,300,400 \mathrm{~m}$ & YUYAN-09 UAV (fixed-wing) & Canon EOS 500D & $4,272 \times 2,848$ & $35 \mathrm{~mm}$ \\
\hline $2010-11$ & $200,300,400 \mathrm{~m}$ & YUYAN-09 UAV (fixed-wing) & Canon EOS 500D & $4,752 \times 3,168$ & $50 \mathrm{~mm}$ \\
\hline 2011-12 & $50,100,200,300 \mathrm{~m}$ & E-Epic UAV (spiral wing) & Canon EOS 500D & $4,752 \times 3,168$ & $35 \mathrm{~mm}$ \\
\hline $2012-13$ & $50,100,200,300 \mathrm{~m}$ & E-Epic UAV (spiral wing) & Canon EOS 5D Mark II & $5,616 \times 3,744$ & $24 \mathrm{~mm}$ \\
\hline 2013-14 & $50,100,200,300 \mathrm{~m}$ & E-Epic UAV (spiral wing) & Panasonic DMC-GH3 & $4,608 \times 2,592$ & $14 \mathrm{~mm}$ \\
\hline
\end{tabular}
were also used to study their relationships between imaging data with disease index or grain yield.

Data analysis. Liner and nonliner data fitting results suggested that the relationships of disease index and yield with image variables

Table 1. Key information for aerial imagery collected in each season 
R, G, B, and I are logarithmic. Therefore R, G, B, and I were logarithmically transformed on the base of 10 , where $\operatorname{lgR}=\log _{10}(\mathrm{R} / 255)$, $\lg G=\log _{10}(\mathrm{G} / 255), \operatorname{lgB}=\log _{10}(\mathrm{~B} / 255)$, and $\lg \mathrm{I}=\log _{10}(\mathrm{I} / 255)$. Correlation of imaging variables with disease index and yield were calculated with the corr.test command in $\mathrm{R}$ (version 3.3.0).

In total, we have 18 datasets (i.e., combinations of year and flight altitude) to assess the relationship of disease index or yield with unmanned aerial digital imagery. For each dataset, there were 21 data points (i.e., individual plots). Random-coefficient regression models were used to study the relationships of disease index and grain yield with imagery variables, focusing on the consistency of such relationships (i.e., variability in the slope and intercept estimates). LME4 package in $\mathrm{R}$ (version 3.3.0) was used to fit random coefficient models.

Because not all flight altitudes were used in all years, we were not able to treat year and flight altitude as separate factors when fitting a random coefficient model. Instead, a single factor was used to represent different combinations of year and flight altitude. Disease index or yield production $\mathrm{y}_{\mathrm{ij}}$ in the $j$ th plot of the $i$ th height-year combination was related to an imaging variable:

$$
\begin{gathered}
y_{i j}=\mu_{i}+x_{i j} \beta_{i}+\varepsilon_{i j}, \\
i=1,2, \ldots, 18 ; j=1,2, \ldots, 21 . \\
\mu_{i} \sim\left(\mu, \sigma_{\mu}^{2}\right), \beta_{i} \sim\left(\beta, \sigma_{\beta}^{2}\right), \varepsilon_{i j} \sim\left(0, \sigma^{2}\right)
\end{gathered}
$$

BLUPs (best linear unbiased predictors) of individual intercepts $\left(\mu_{\mathrm{i}}\right)$ and slopes $\left(\beta_{\mathrm{i}}\right)$ are generated by the LME4 package (R version 3.3.0).

\section{Results}

Correlations between unmanned aerial digital image variables and disease index. Figure 1 shows the correlation of disease index with unmanned aerial digital image variables. $\lg \mathrm{R}, \lg \mathrm{G}, \lg \mathrm{B}$, and $\operatorname{lgI}$ were significantly correlated positively with disease index at all different flight altitudes over the five seasons. Correlation coefficients of disease index with $\lg R, \lg \mathrm{G}, \operatorname{lgB}$, and $\lg \mathrm{I}$ ranged from 0.61 to $0.91,0.58$ to $0.88,0.53$ to 0.92 , and 0.60 to 0.92 , respectively $\mathrm{H}, \mathrm{G} / \mathrm{R}$, and $\mathrm{G}-\mathrm{R}$ were negatively correlated with disease index, with the correlation ranging from -0.83 to $-0.53,-0.91$ to -0.46 , and -0.87 to -0.42 , respectively. $(\mathrm{R}-\mathrm{G}) /(\mathrm{G}+\mathrm{R})$ was positively correlated with disease index, while $\mathrm{S}$ did not show a consistent correlation with
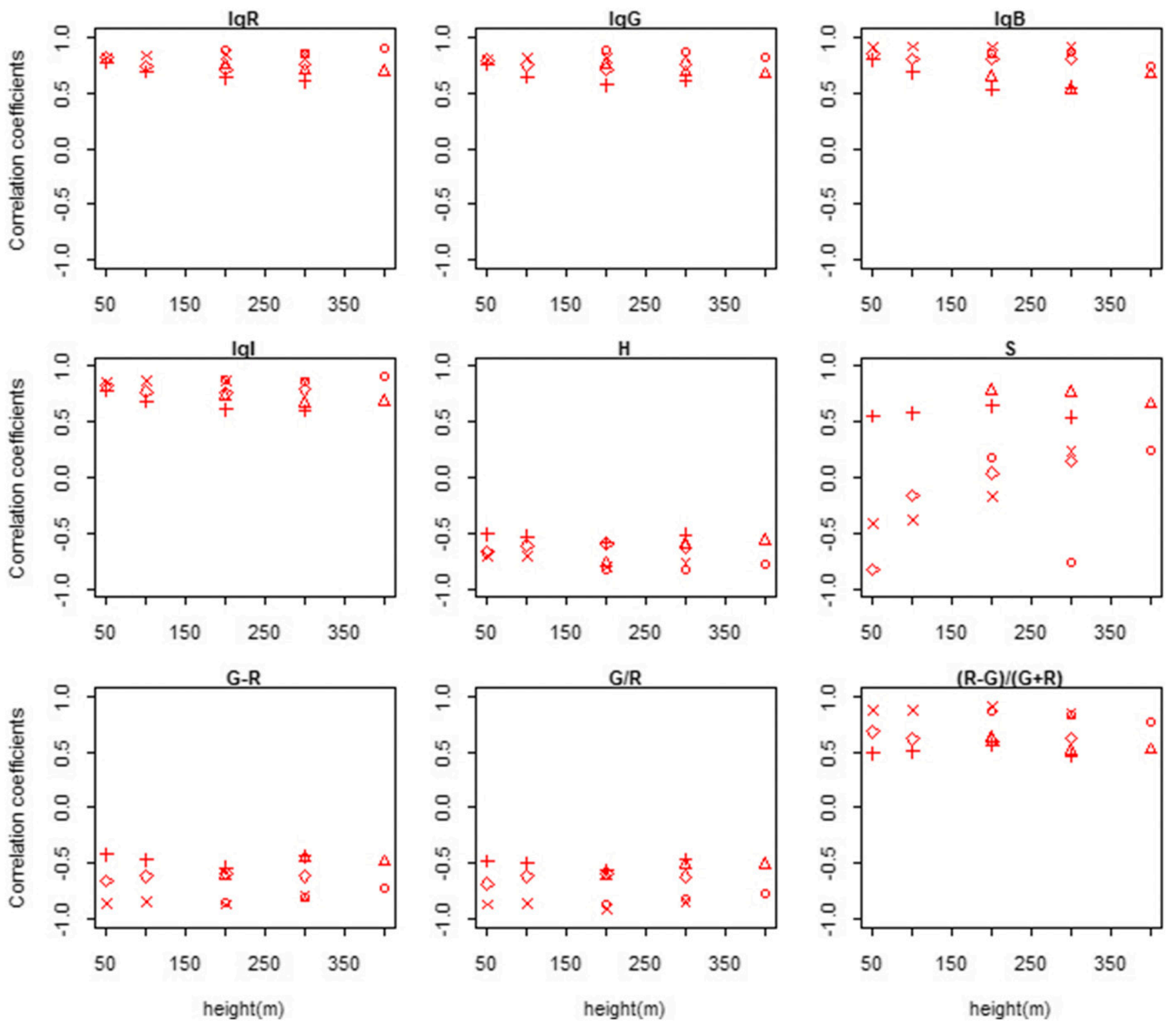

Fig. 1. Coefficients of correlation of winter wheat powdery mildew index with imaging variables extracted from digital images at five flight altitudes over five seasons. ' $O$,' ' $\triangle$, ' '+, ' $\times$,' and ' $V$ ' represent the years 2010, 2011, 2012, 2013, and 2014, respectively; R, G, B, I, H, S means the value of red, green, blue, intensity, hue, and saturation acquired from aerial photography, respectively; $\lg R, \lg G, \lg B$, and $\lg$ means the logarithms of the value of red, green, blue, and intensity, respectively; $G / R, G-R$, and $(G-R) /(G+R)$ are composite variables that combine the values of red and green. 
disease index. There was considerable variability in the magnitude of the correlation among 18 year-height combinations, especially between years.

Modeling relationships of disease indices with imaging variables. As $\operatorname{lgR}$ had the greatest and most consistent correlation with disease index, only $\operatorname{lgR}$ was used in random-coefficient regression modeling. For the intercept, $\mu$ and $\sigma_{\mu}^{2}$ were estimated to be $-814.51 \pm 72.91$ and 54,455 , respectively; the corresponding values for the slope $\left(\beta\right.$ and $\sigma_{\beta}^{2}$ ) were $458.67 \pm 38.36$ and 15,336 , respectively. All four estimates were significantly different from zero. Residual variance $\left(\sigma^{2}\right)$ was 188 . The fitted random coefficient regression models are shown in Figure 2, which shows considerable differences in the BLUPs of intercept and slopes, particularly between years.

There is near perfect negative correlation $(\mathrm{r}=-0.99)$ between BLUPs of intercept and slope estimates (Fig. 3). The relationship can be expressed as: $\mu_{\mathrm{i}}=(-1.82 \pm 0.085) \times \beta_{\mathrm{i}}+(22.85 \pm 39.832)$. The variability disease index with $\operatorname{lgR}$ based on the $10 \%, 50 \%$, and 90\% quantile fitted models are shown in Figure 4, which graphically illustrates the variability in the relationship.

Correlations between unmanned aerial digital image parameters and grain yield. Correlations between grain yield and variables extracted from unmanned aerial digital imagery are given in Table 2. There were large differences in these correlation coefficients among the 18 year-height combinations, particularly between years. Grain yield was correlated negatively with $\lg R, \lg \mathrm{G}, \lg \mathrm{I}, \lg \mathrm{B}$, and $(\mathrm{R}-\mathrm{G}) /$ $(\mathrm{R}+\mathrm{G})$, and positively with $\mathrm{H}, \mathrm{G}-\mathrm{R}$, and $\mathrm{G} / \mathrm{R}$. In contrast, correlation of grain yield with $\mathrm{S}$ was inconsistent, ranging from 0.75 to -0.78 .

Relationships of wheat yield production with imaging variables. Because of its high and consistent correlation with grain yield, only $\operatorname{lnR}$ was used in random coefficient regression modeling. The fitted model was as follows: Yield $\mathrm{ij}_{\mathrm{ij}}=\mu_{\mathrm{I}}+\left(\operatorname{lgR}_{\mathrm{ij}}\right) \beta_{\mathrm{i}}+\varepsilon_{\mathrm{ij}}, \mu_{\mathrm{i}} \sim(21.37 \pm 3.122$, 153.07), $\beta_{\mathrm{i}} \sim(-9.14 \pm 1.584,39.20), \varepsilon_{\mathrm{ij}} \sim(0,0.0766)$. Both $\sigma_{\mu}^{2}$ and $\sigma_{\beta}^{2}$ were significantly greater than zero, indicating significant differences in the intercept and slope among the 18 year-height combinations. As for mildew index, there appeared to be greater variability in the $\operatorname{lgR}$ yield relationship among years at a given height than among heights within the same year (Fig. 5).

The correlation between BLUPs of slopes and intercepts was -0.999 (Fig. 6). The relationship was: $\mu_{i}=(-1.98 \pm 0.025) \times \beta_{i}+$ $(3.28 \pm 0.265)$. The variability yield estimation with $\operatorname{lgR}$ based on the $10 \%, 50 \%$, and $90 \%$ quantile fitted models is shown in Figure 7; this also graphically illustrates the variability between yield and parameter $\lg R$.

\section{Discussion}

Unmanned aerial digital images were acquired at Feekes growth stage (GS) 10.5.4 from 50, 100, 200, 300, and $400 \mathrm{~m}$ above the ground in five consecutive seasons. Most imaging variables extracted from the digital photography were highly correlated to the disease
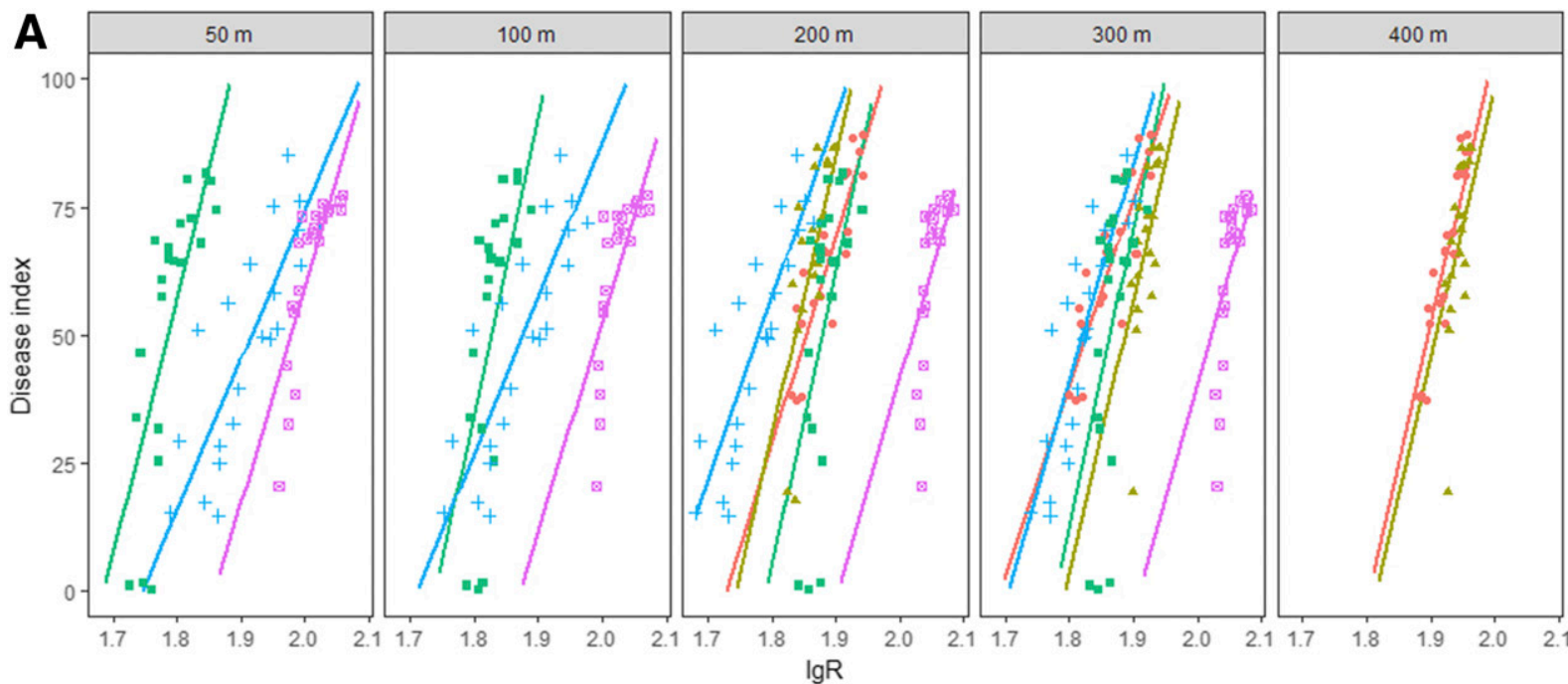

$$
\begin{aligned}
& \text { factor(Year) } \\
& \rightarrow 2010 \\
& -2011 \\
& \rightarrow 2012 \\
& \rightarrow 2013 \\
& -2014 \\
& \text { Year } \\
& \text { - } 2010 \\
& \text { - } 2011 \\
& -2012 \\
& +2013 \\
& \text { ø } 2014
\end{aligned}
$$
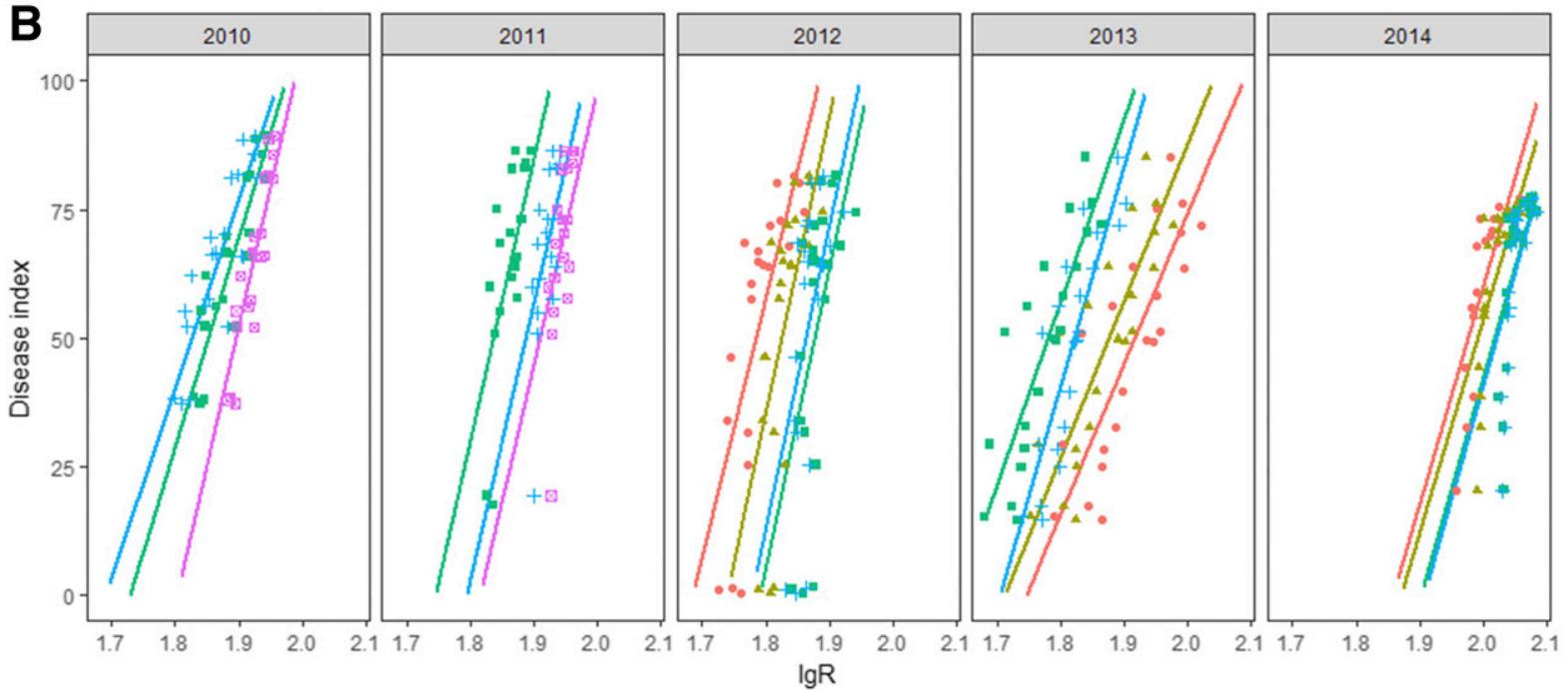

Height

- $50 \mathrm{~m}$

A $100 \mathrm{~m}$

- $200 \mathrm{~m}$

$+300 \mathrm{~m}$

๑ $400 \mathrm{~m}$

factor(Height)

$\rightarrow 50 \mathrm{~m}$

$\rightarrow 100 \mathrm{~m}$

$\rightarrow 200 \mathrm{~m}$

$\rightarrow 300 \mathrm{~m}$

$\rightarrow 400 \mathrm{~m}$

Fig. 2. Fitted random coefficient models relating $\lg R$ (an imaging variable extracted from unmanned aerial digital photography) to powdery mildew index on winter wheat at the same flight altitude among different years (A), and in the same year among different flight altitudes (B). 
index of wheat powdery mildew and grain yield. However, the exact relationships varied considerably among combinations of survey years and flight altitudes, particularly among years.

Among all image features extracted from unmanned aerial digital photography, the color feature $\operatorname{lgR}$ is most highly and consistently correlated positively with powdery mildew index. Red reflectance values decrease as the nitrogen application rate increases (Jia et al. 2004; Zubillaga and Urricariet 2005). It would be interesting to assess whether red reflectance can differentiate the effect on canopy characteristics due to powdery mildew and nitrogen input. Wheat grain yield was negatively correlated with $\lg R$, similar to a previous study that reported that there were significant negative correlations between corn yield and parameter R (Blackmer and Schepers 1996).

Random-coefficient regression modeling indicated that the exact relationships of grain yield or disease index with $\operatorname{lgR}$ varied significantly with survey year and flight altitude, particularly between years. For example, when randomly sampled $\lg \mathrm{R}$ was 1.9 , the disease index and yield values estimated by $10 \%, 50 \%$, and $90 \%$ quantile models can be 46.85, 59.54, and 72.24; and 4.653, 4.011, and 3.369297 , respectively. The variability in the relationships of $\lg R$ with disease index and grain yield is less between flight altitudes within the same year is also supported by fixed effect regression (results not shown). Ground resolution of the images and camera focal length are likely to be the main reasons for the variability observed in the image-disease index relationship between different flight heights. The camera focal length and image resolution were preset to the same in each year for all flight altitudes. Thus, the higher the flight altitude is, the greater coverage in photos, leading to decreased resolution with increasing flight altitude. However, it should be noted that, for a given year, the image data at different flight altitudes were obtained on the same day for the same wheat planting. Nevertheless, the condition in the weeks before and at the day when imaging was taken may differ considerably among years. Thus, differences in factors (e.g., weather conditions, plant growth vigor/nutrient status, and some other unknown reasons) that could affect remote digital photography are expected to be greater between years than between flight altitudes in the same year. In addition, we tried to have the same lighting conditions by measuring at similar times of day in similar weather conditions, but we used three brands of camera and two brands of UAV in the five years. Different brands of UAVs and cameras have different systems (e.g., metering system, focusing systems, and image sensor systems). Furthermore, different camera calibration standards may lead to differences in the color rendition. The differences in UAV and camera are expected to contribute to the observed between-year variability in the relationship of image features with disease or yield. To assess the relative effects of between- and within-year variability on the relationship of disease or grain yield with digital image features, further experiments need to be carried out in which images are taken on different days for different plantations. Moreover, images should be saved in RAW format, with standard color as a reference, through the use of standard color plate (such as Pantone) to calibrate the photographs. In addition, a large range of disease severities among plots would be desirable, particularly plots with very low or no diseases that may be used to calibrate imaging data for the year-to-year differences in crop development/ characteristics.

The use of aerial photographs has been used to study the occurrence (Everitt et al. 1999; Martins et al. 2001) and epidemic (Johnson et al. 2003) of plant diseases. Previous studies have focused on demonstrating that imaging features are related to traits of our interests, e.g., disease, yield, and canopy structure. However, the consistency (repeatability) of such a relationship has not yet received much attention. This consistency is crucially important in determining whether the imaging technology can be used in practice and, if so, what the scope of its application is. The present study, on the one hand, shows that certain image features are highly correlated with disease index and grain yield. On the other hand, it also shows that we cannot ignore the variability in the relationship of image features with disease or grain yield (Fig. 4 and Fig. 7). In addition, BLUPs of the slope and intercept have near perfect negative correlations; thus effectively, there is only one parameter to estimate. This needs to be taken into consideration in future research. For example, when conducting simulation studies, we cannot independently sample the

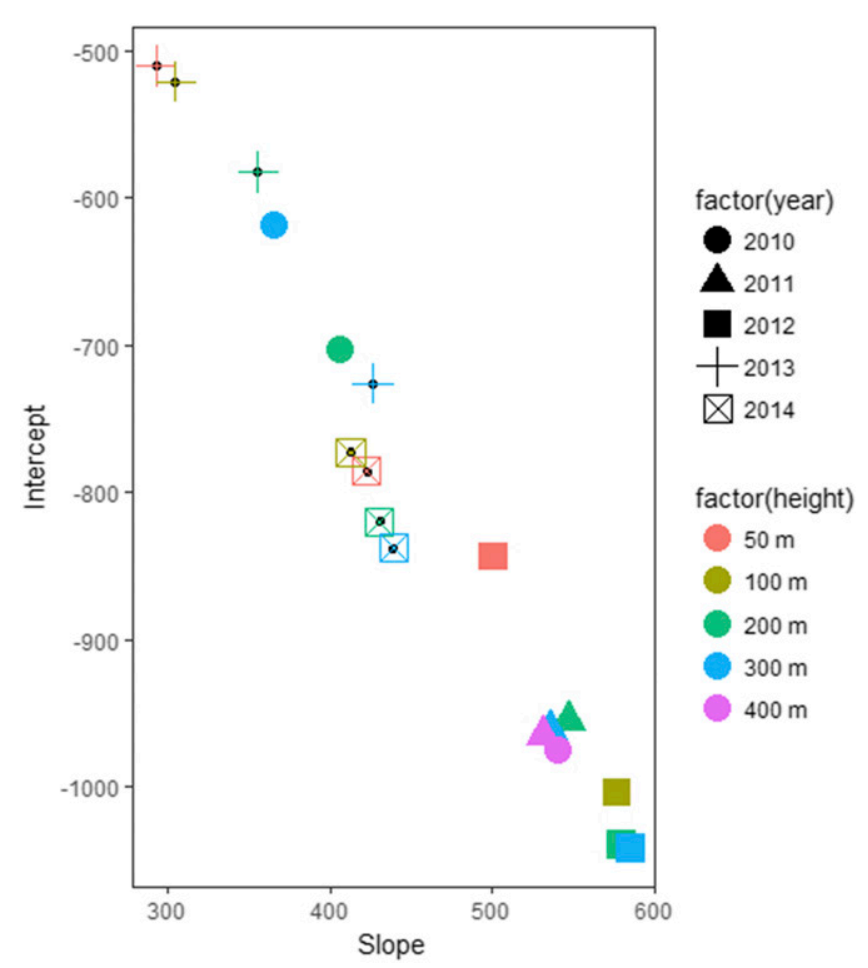

Fig. 3. BLUPs (best linear unbiased predictors) of the slopes and intercepts describing the relationship of winter wheat powdery mildew with IgR (an imaging variable extracted from unmanned aerial digital photography).

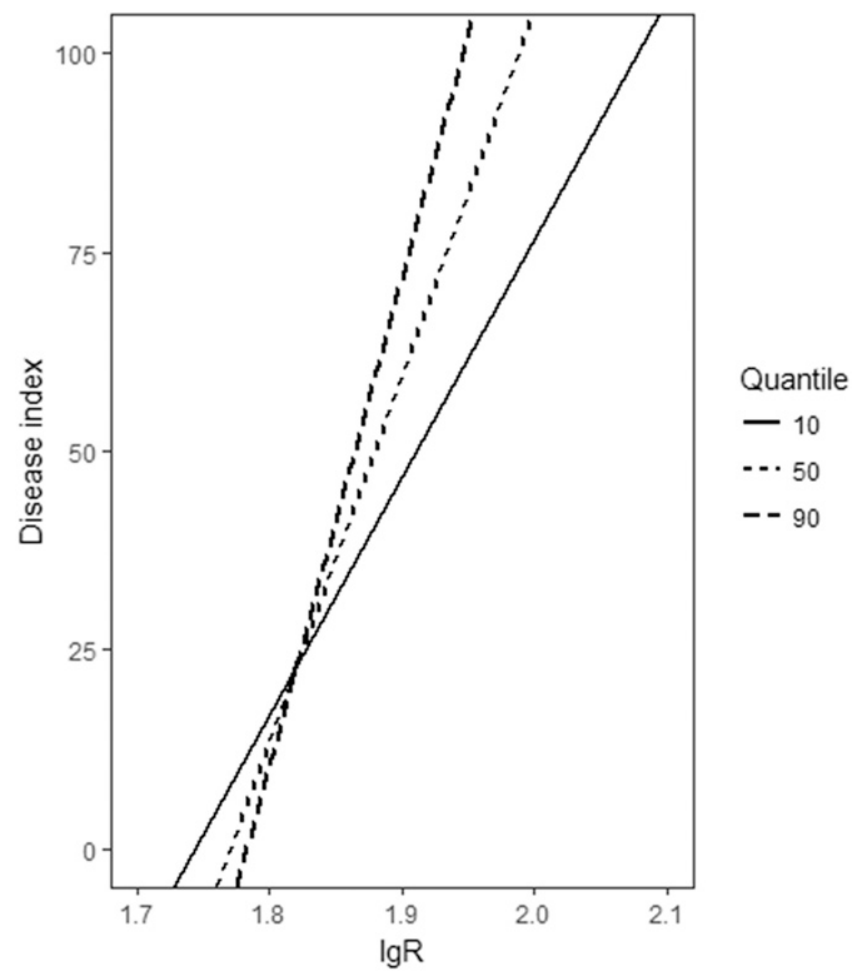

Fig. 4. The variability disease index of wheat powdery mildew with parameter lgR (an imaging variable extracted from unmanned aerial digital photography) based on the $10 \%, 50 \%$, and $90 \%$ quantile fitted models. 
Table 2. Coefficients of correlation between unmanned aerial digital parameters at 50, 100, 200, 300, and $400 \mathrm{~m}$ flight altitude and grain yield during five seasons ${ }^{\mathbf{a}}$

\begin{tabular}{|c|c|c|c|c|c|c|c|c|c|c|}
\hline Year & Height & $\lg R$ & $\lg G$ & $\lg B$ & $\lg I$ & $\mathbf{H}$ & $\mathbf{S}$ & G-R & G/R & $(\mathbf{R}-\mathbf{G}) /(\mathbf{R}+\mathbf{G})$ \\
\hline 2010 & 200 & $-0.8110^{* *}$ & $-0.8093^{* *}$ & $-0.8064 * *$ & $-0.8202 * *$ & $0.7410^{* *}$ & -0.0898 & $0.7995^{* *}$ & $0.7977 * *$ & $-0.8005^{* *}$ \\
\hline 2010 & 300 & $-0.8197 * *$ & $-0.8170^{* *}$ & $-0.8503 * *$ & $-0.8296 * *$ & $0.7972 * *$ & $0.6983^{* *}$ & $0.7995^{* *}$ & $0.8058^{* *}$ & $-0.8075^{* *}$ \\
\hline 2010 & 400 & $-0.8412 * *$ & $-0.7553 * *$ & $-0.7913 * *$ & $-0.8442 * *$ & $0.6155^{* *}$ & -0.3709 & $0.6235^{* *}$ & $0.6680 * *$ & $-0.6602 * *$ \\
\hline 2011 & 200 & $-0.6837 * *$ & $-0.6913 * *$ & $-0.6323 * *$ & $-0.6798 * *$ & $0.6671 * *$ & $-0.6037 * *$ & $0.5880 * *$ & $0.5892 * *$ & $-0.5901 * *$ \\
\hline 2011 & 300 & $-0.6545 * *$ & $-0.6209 * *$ & -0.4411 & $-0.5988 * *$ & $0.7021 * *$ & $-0.7791 * *$ & $0.5967 * *$ & $0.6352 * *$ & $-0.6356^{* *}$ \\
\hline 2011 & 400 & $-0.6541 * *$ & $-0.5933 * *$ & $-0.5881 * *$ & $-0.6205^{* *}$ & $0.6698 * *$ & $-0.6538 * *$ & $0.6261^{* *}$ & $0.6411^{* *}$ & $-0.6413 * *$ \\
\hline 2012 & 50 & $-0.7794 * *$ & $-0.7997 * *$ & $-0.7976^{* *}$ & $-0.7994 * *$ & 0.4279 & $-0.6868 * *$ & 0.3569 & 0.3919 & -0.398 \\
\hline 2012 & 100 & $-0.6902 * *$ & $-0.7347 * *$ & $-0.659 * *$ & $-0.7134 * *$ & 0.3934 & $-0.7775^{* *}$ & 0.3400 & 0.354 & -0.3595 \\
\hline 2012 & 200 & $-0.5232 *$ & $-0.5023^{*}$ & -0.3491 & $-0.4912 *$ & $0.4438^{*}$ & $-0.7193 * *$ & 0.4198 & 0.4188 & -0.422 \\
\hline 2012 & 300 & $-0.4473^{*}$ & $-0.5211^{*}$ & -0.3224 & $-0.4456^{*}$ & 0.3005 & $-0.5751 * *$ & 0.2553 & 0.2593 & -0.2629 \\
\hline 2013 & 50 & $-0.5727 * *$ & $-0.5486^{* *}$ & $-0.6848 * *$ & $-0.6051 * *$ & $0.4854^{*}$ & 0.4242 & $0.6667 * *$ & $0.6428 * *$ & $-0.6436^{* *}$ \\
\hline 2013 & 100 & $-0.5874 * *$ & $-0.5649 * *$ & $-0.6924 * *$ & $-0.6179 * *$ & $0.4963 *$ & 0.3969 & $0.6699 * *$ & $0.6516^{* *}$ & $-0.6519 * *$ \\
\hline 2013 & 200 & $-0.6048 * *$ & $-0.5811^{* *}$ & $-0.7119 * *$ & $-0.6349 * *$ & $0.5270^{*}$ & 0.2592 & $0.5982 * *$ & $0.6230^{* *}$ & $-0.6246^{* *}$ \\
\hline 2013 & 300 & $-0.6514 * *$ & $-0.6342^{* *}$ & $-0.7464 * *$ & $-0.6766 * *$ & $0.5409 *$ & -0.0736 & $0.5854 * *$ & $0.6087^{* *}$ & $-0.6104 * *$ \\
\hline 2014 & 50 & $-0.7740 * *$ & $-0.7466^{* *}$ & $-0.7962 * *$ & $-0.7745^{* *}$ & $0.6749 * *$ & $0.7503 * *$ & $0.6668^{* *}$ & $0.6812^{* * *}$ & $-0.6801 * *$ \\
\hline 2014 & 100 & $-0.8327 * *$ & $-0.7942 * *$ & $-0.7871 * *$ & $-0.8178^{* *}$ & $0.8157 * *$ & -0.1257 & $0.8243 * *$ & $\mathrm{0.8196}^{* *}$ & $-0.8215^{* *}$ \\
\hline 2014 & 200 & $-0.8118 * *$ & $-0.7408 * *$ & $-0.7535^{* *}$ & $-0.7999 * *$ & $0.7724 * *$ & -0.3004 & $0.7800 * *$ & $0.7749 * *$ & $-0.7764 * *$ \\
\hline 2014 & 300 & $-0.8324 * *$ & $-0.7630 * *$ & $-0.7871 * *$ & $-0.8192 * *$ & $0.7954 * *$ & -0.3285 & $0.8002 * *$ & $0.7985^{* *}$ & $-0.7993 * *$ \\
\hline
\end{tabular}

a Values in bold indicate the highest correlation values. Asterisk $(*)$ indicates correlation coefficient significant at $P=0.05,(* *)$ indicates correlation coefficient significant at $P=0.01$.
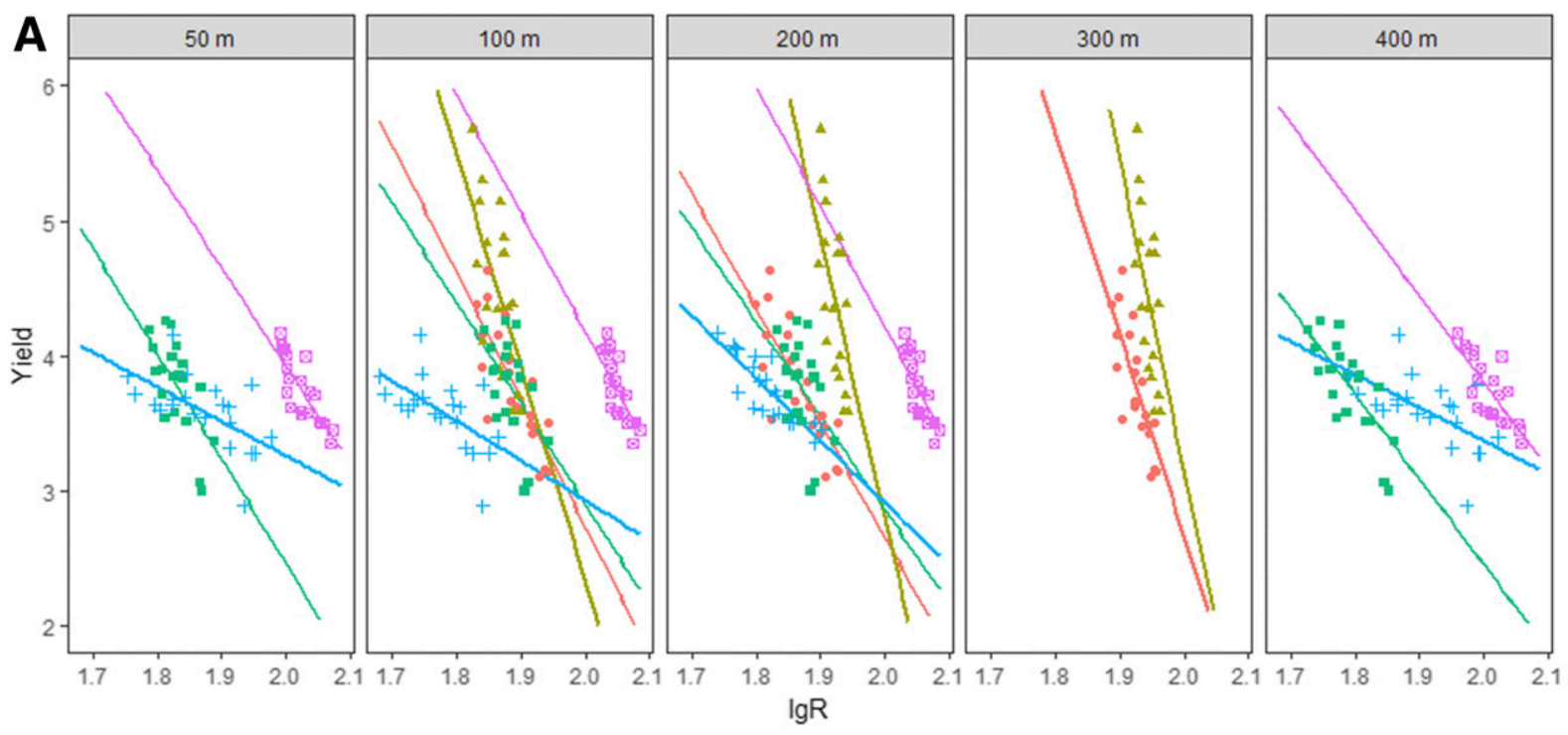

$$
\begin{aligned}
& \text { factor(Year) } \\
& +2010 \\
& +2011 \\
& -2012 \\
& +2013 \\
& -2014 \\
& \text { Year } \\
& \text { - } 2010 \\
& \text { - } 2011 \\
& \text { - } 2012 \\
& +2013 \\
& \text { - } 2014
\end{aligned}
$$

\section{B}
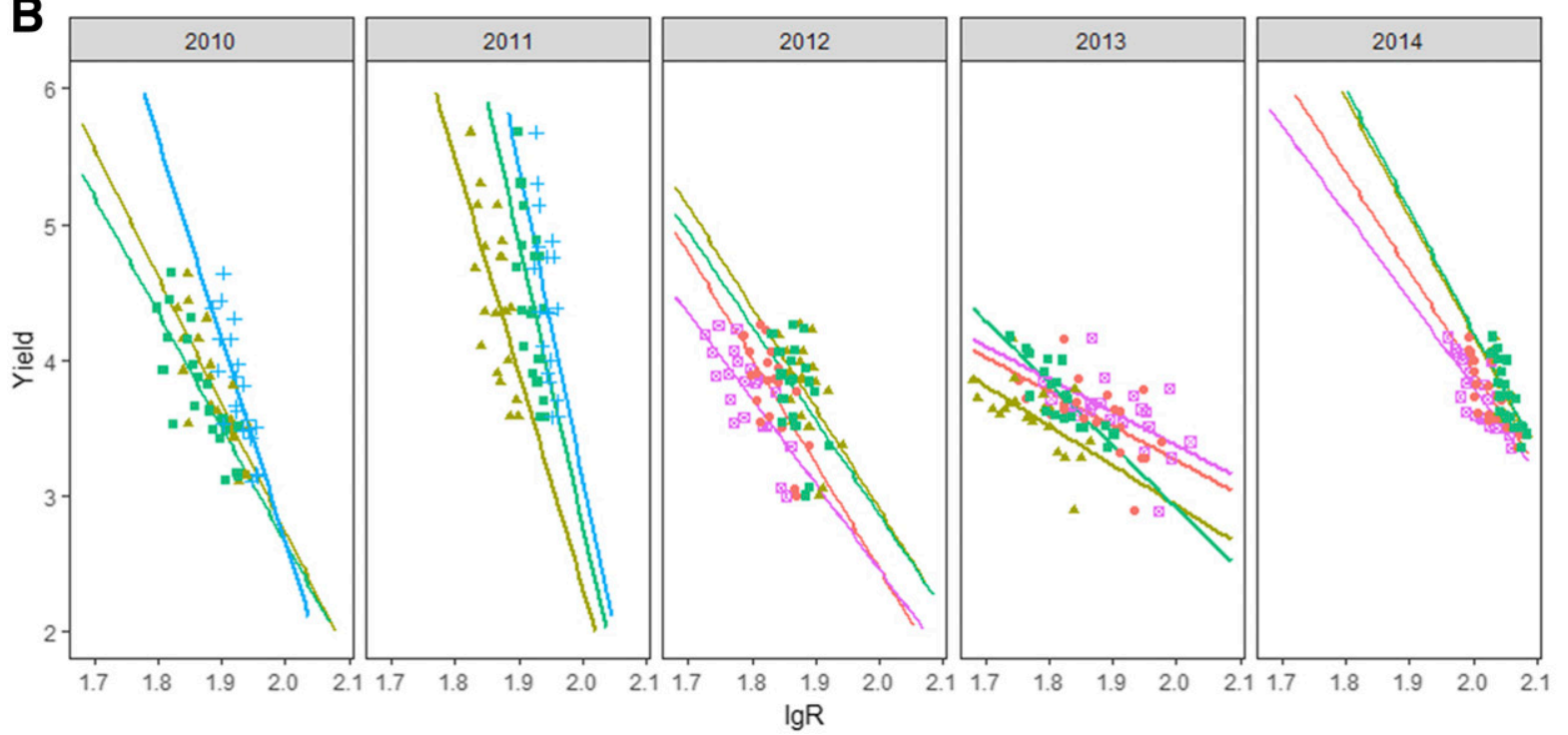

Height

- $50 \mathrm{~m}$

- $100 \mathrm{~m}$

- $200 \mathrm{~m}$

$+300 \mathrm{~m}$

ฮ $400 \mathrm{~m}$

factor(Height)

$\rightarrow 50 \mathrm{~m}$

$-100 \mathrm{~m}$

$\rightarrow 200 \mathrm{~m}$

$\rightarrow 300 \mathrm{~m}$

$-400 \mathrm{~m}$

Fig. 5. Fitted random coefficient models relating lgR (an imaging variable from unmanned aerial digital photography) to wheat grain yield at the same flight altitude among different years $(\mathbf{A})$, and in the same year among different flight altitudes (B). 
intercept and slope from the estimated normal distributions. Otherwise, we might have invalid output, e.g., negative yield or disease.

In summary, the present results demonstrate that relationships of image features with winter wheat powdery mildew and yield varied

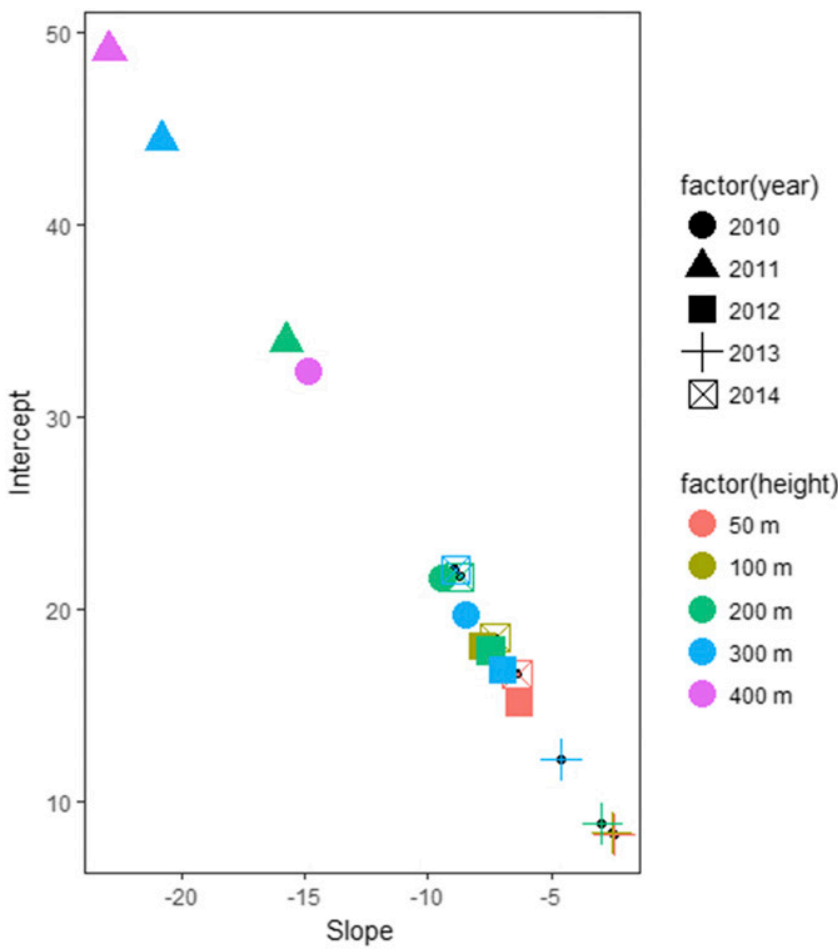

Fig. 6. BLUPs (best linear unbiased predictors) of the slopes and intercepts describing the relationship of winter wheat grain yield with lgR (an imaging variable extracted from unmanned aerial digital photography).

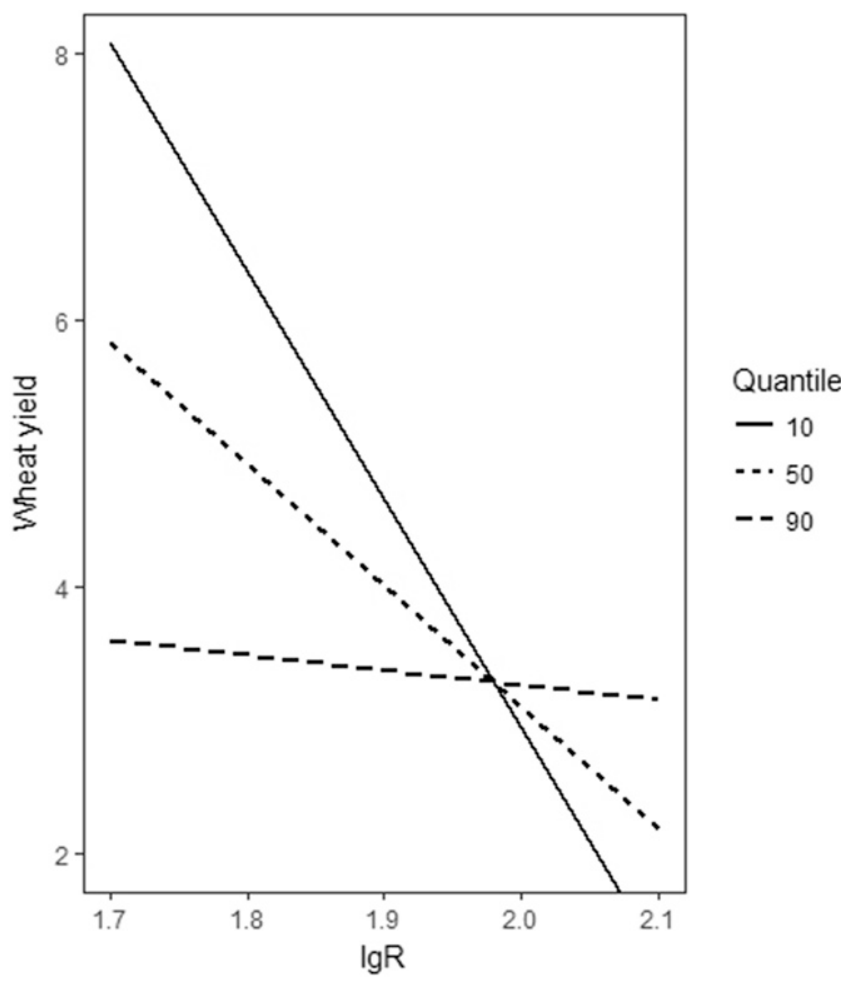

Fig. 7. The variability yield estimation with parameter $\lg R$ (an imaging variable extracted from unmanned aerial digital photography) based on the $10 \%, 50 \%$, and $90 \%$ quantile fitted models. considerably among years and, to a lesser extent, with flight altitudes. With the rapidly increasing image resolution and capacity for storing and processing digital data (Bock et al. 2010), and the flexibility, stability, and operability of UAV platforms, unmanned aerial digital photography is perceived to be valuable in the assessment of plant disease and estimation of yield. The present results demonstrated that further research is necessary to define the scope within which such a UAV-based imaging system can be used in practice.

\section{Literature Cited}

Adamsen, F. G., Pinter, P. J., Barnes, E. M., LaMorte, R. L., Wall, G., Leavitt, S. W., and Kimball, B. A. 1999. Measuring wheat senescence with a digital camera. Crop Sci. 39:719-724.

Aparicio, N., Villegas, D., Casadesus, J., Araus, J. L., and Royo, C. 2000. Spectral vegetation indices as nondestructive tools for determining durum wheat yield. Agron. J. 92:83-91.

Babar, M. A., Reynolds, M. P., Ginkel, M. V., Klatt, A. R., Raun, W. R., and Stone, M. 2006. Spectral reflectance indices as a potential indirect selection criteria for wheat yield under irrigation. Crop Sci. 46:578-588.

Berni, J. A. J., Zarco-Tejada, P. J., Suárez, L., González-Dugo, V., and Fereres, E. 2009. Remote sensing of vegetation from UAV platforms using lightweight multispectral and thermal imaging sensors. In: Proceedings of the ISPRS Workshop. High-Resolution Earth Imaging for Geospatial Information. Hannover, Germany, 2-5 June 2009.

Blackmer, T. M., and Schepers, J. S. 1996. Aerial photography to detect nitrogen stress in corn. J. Plant Physiol. 148:440-444.

Bock, C. H., Poole, G. H., Parker, P. E., and Gottwald, T. R. 2010. Plant disease severity estimated visually, by digital photography and image analysis, and by hyperspectral imaging. Crit. Rev. Plant Sci. 29:59-107.

Cao, X. R., Luo, Y., Zhou, Y. L., Duan, X. Y., and Cheng, D. F. 2013. Detection of powdery mildew in two winter wheat cultivars using canopy hyperspectral reflectance. Crop Prot. 45:124-131.

Cao, X. R., Luo, Y., Zhou, Y. L., Fan, J. R., Xu, X. M., West, J. S., Duan, X. Y., and Cheng, D. F. 2015. Detection of powdery mildew in two winter wheat plant densities and prediction of grain yield using canopy hyperspectral reflectance. PLoS One 10:e0121462.

Cao, X. R., Yao, D. M., Duan, X. Y., Liu, W., Fan, J. R., Ding, K. J., and Zhou, Y. L. 2014. Effects of powdery mildew on 1000-kernel weight, crude protein content and yield of winter wheat in three consecutive growing seasons. J. Integr. Agric. 13:1530-1537.

Cheng, H. D., Jiang, X. H., Sun, Y., and Wang, J. L. 2001. Color image segmentation: advances and prospects. Pattern Recognit. 34:2259-2281.

Clark, R. V., Galway, D. A., and Paliwal, Y. C. 1981. Aerial infrared photography for disease detection in field plots of barley oats and wheat. Phytopathology 71 : 867.

Colwell, R. N. 1956. Determining the prevalence of certain cereal crop diseases by means of aerial photography. Calif. Agric. 26:223-286.

de Castro, A. I., Ehsani, R., Ploetz, R. C., and Crane, J. H. 2015. Detection of laure wilt disease in Avocado using low altitude aerial imaging. PLoS One 10 e0124642.

Everitt, J. H., Escobar, D. E., Appel, D. N., Riggs, W. G., and Davis, M. R. 1999 Using airborne digital imagery for detecting oak wilt disease. Plant Dis. 83: 502-505.

Franke, J., and Menz, G. 2007. Multi-temporal wheat disease detection by multispectral remote sensing. Precis. Agric. 8:161-172.

Garcia-Ruiz, F., Sankaran, S., Maja, J. M., Lee, W. S., and Rasmussen, J. 2013. Comparison of two aerial imaging platforms for identification of Huanglongbing-infected citrus trees. Comput. Electron. Agric. 91:106-115.

Gonzalez, R. C., and Wintz, P. 1977. Digital Image Processing. Addison-Wesley, Reading, MA.

Huntsherger, T. L., Jacobs, C. L., and Cannon, R. L. 1985. Iterative fuzzy image segmentation. Pattern Recognit. 18:131-138.

Jannoura, R., Brinkmann, K., Uteau, D., Bruns, C., and Goergensen, R. G. 2015. Monitoring of crop biomass using true colour aerial photographs taken from a remote controlled hexacopter. Biosyst. Eng. 129:341-351.

Jia, L., Buerkert, A., Chen, X., Roemheld, V., and Zhang, F. 2004. Low-altitude aerial photography for optimum $\mathrm{N}$ fertilization of winter wheat on the North China Plain. Field Crops Res. 89:389-395.

Johnson, D. A., Alldredge, J. R., Hamm, P. B., and Frazier, B. E. 2003. Aerial photography used for spatial pattern analysis of late blight infection in irrigated potato circles. Phytopathology 93:805-812.

Kampmann, H. H., and Hansen, O. B. 1994. Using colour image analysis for quantitative assessment of powdery mildew on cucumber. Euphytica 79:19-27.

Karcher, D. E., and Richardson, M. D. 2003. Quantifying turfgrass color using digital image analysis. J. Crop Sci. 43:943-951.

Kim, W. S., and Park, R. H. 1996. Color image palette construction based on the HSI color system for minimizing the reconstruction error. Pages 1041-1044 in: Proceedings of the 3rd IEEE International Conference on Image Processing.

Large, E. C. 1954. Growth stages in cereals. Illustration of the Feekes scale. Plant Pathol. 3:128-129. 
Li, X. H., Lee, W. S., Li, M. Z., Ehsani, R., Mishra, A. R., Yang, C. H., and Mangan, R. L. 2012. Spectral difference analysis and airborne imaging classification for citrus greening infected trees. Comput. Electron. Agric. 83:32-46.

Martins, L. M., Lufinha, M. I., Marques, C. P., and Abreu, C. G. 2001. Small format aerial photography to assess chestnut ink disease. For. Snow Landsc. Res. 73:357-360.

Mirik, M., Jones, D. C., Price, J. A., Workneh, F., Ansley, R. G., and Rush, C. M. 2011. Satellite remote sensing of wheat infected by wheat streak mosaic virus. Plant Dis. 95:4-12.

Nagarajan, S., Seibold, G., Kranza, J., Saari, E. E., and Joshi, L. M. 1984. Monitoring wheat rust epidemics with the Landsat-2 satellite. Phytopathology 74:585-587.

Nilsson, H. E. 1995. Remote sensing and image analysis in plant pathology. Can. J. Plant Pathol. 17:154-166.

Opalski, K. S., Tresch, S., Kogel, K. H., Grossmann, K., Köhle, H., and Hückelhoven, R. 2006. Metrafenone: studies on the mode of action of a novel cereal powdery mildew fungicide. Pest Manag. Sci. 62:393-401.

Petersen, S. 2015. Advancing marker-assisted selection for resistance to powdery mildew and Fusarium head blight in wheat. North Carolina State University, Raleigh, NC.

Saari, E. E., and Prescott, J. M. 1975. Scale for appraising the foliar intensity of wheat diseases. Plant Dis. Rep. 59:377-380.

Schepers, H., Bouma, E., Frahm, J., Wolk, T., Secher, B.J.M., 1996. Control of fungal diseases in winter wheat with appropriate dose rates and weatherbased decision support systems. EPPO Bull. 26:623-630.

Shanahan, J. F., Schepers, J. S., Francis, D. D., Varvel, G. E., Wilhelm, W. W., Tringe, J. M., Schlemmer, M. R., and Major, D. J. 2001. Use of remotesensing imagery to estimate corn grain yield. Agron. J. 93:583-589.
Sheng, B. Q., and Duan, X. Y. 1991. Improvement of scale 0-9 method for scoring adult plant resistance to powdery mildew of wheat. Beijing Agric. Sci. 1:38-39.

Steddom, K., Mcmullen, M., Schatz, B., and Rush, C. M. 2004. Assessing foliar disease of wheat image analysis. Pages 32-38 in: Proceedings of the Summer Crops Field Day Sponsored by the Cooperative Research, Education \& Extension Team (CREET'04).

Toler, R. W., Smith, B. D., and Harlan, J. C. 1981. Use of aerial color infrared photography to evaluate crop disease. Plant Dis. 65:24.

Vega, F. A., Ramírez, F. C., Saiz, M. P., and Rosúa, F. O. 2015. Multi-temporal imaging using an unmanned aerial vehicle for monitoring a sunflower crop. Biosyst. Eng. 132:19-27.

Wallen, V. R., and Jackson, H. R. 1971. Aerial photography as a survey technique for the assessment of bacterial blight of field beans. Can. Plant Dis. Surv. 51: 163-169.

Wolfe, M. S. 1984. Trying to understand and control powdery mildew. Plant Pathol. 33:451-466.

Zarco-Tejada, P. J., González-Dugo, V., and Berni, J. A. J. 2012. Fluorescence, temperature and narrow-band indices acquired from a UAV platform for water stress detection using a micro-hyperspectral imager and a thermal camera. Remote Sens. Environ. 117:322-337.

Zhang, J. C., Pu, R. L., Wang, J. H., Huang, W. J., Yuan, L., and Luo, J. H. 2012. Detecting powdery mildew of winter wheat using leaf level hyperspectral measurements. Comput. Electron. Agric. 85:13-23.

Zhang, J. C., Pu, R. L., Yuan, L., Wang, J. H., Huang, W. J., and Yang, G. J. 2014 Monitoring powdery mildew of winter wheat by using moderate resolution multi-temporal satellite imagery. PLoS One 9:e93107.

Zubillaga, M., and Urricariet, S. 2005. Assessment of nitrogen status in wheat using aerial photography. Commun. Soil Sci. Plant Anal. 36:1787-1798. 